\title{
EL PROCESO DE VISUALIZACIÓN DESDE LA PERSPECTIVA DE LA RESPONSABILIDAD SOCIAL CORPORATIVA
}

\section{THE VISUALIZATION PROCESS FROM THE PERSPECTIVE OF CORPORATE SOCIAL RESPONSIBILITY}

Luis Felipe Solano Santos: Facultad de Ciencias de la Información de la Universidad Complutense de Madrid. (España)

felipe.solano@ccinf.ucm.es

\section{CURRÍCULUM VITAE}

Doctor en Ciencias de la Información. Licenciado en Periodismo por la Facultad de Ciencias de la Información de la Universidad Complutense de Madrid (España). Es miembro de un Grupo de Investigación Validado Complutense y director de varios proyectos de investigación. Ponente en varios Congresos nacionales e internacionales. Ha publicado tres libros y numerosos artículos en libros y revistas científicas.

\section{RESUMEN}

El proceso de establecimiento de la misión, visión y valores, se denomina Proceso de Visualización, en el cual se proyecta la imagen de excelencia que se desea crear. La Misión es la razón de ser de una persona, equipo y empresa, con lo quele permite existir, lograr su sostenibilidad o rentabilidad; es el propósito central por el que se crea un ente. La Visión Estratégica es una imagen del futuro deseado que buscamos crear con nuestros esfuerzos y acciones; es la organización en el futuro. Los valores 
son los puntales que le brindan a las organizaciones, su fortaleza,su poder y fortalecen la Visión. Dependen de las normas éticas y el comportamiento de gestión. Todo esto se ha convertido en una técnica de comunicación interna y de creación de imagen.

\section{PALABRAS CLAVE}

Proceso de visualización - Comunicación - Imagen - Empresa - Responsabilidad Social Corporativa

\section{ABSTRACT}

The process of establishing the mission, vision and values, is called the Display Process, which projects the image of excellence to be created. The Mission is the reason for an individual, team and company, so quele allowed to exist, achieve sustainability and profitability is the main purpose for establishing an entity. The Strategic Vision is an image of the desired future that we create with our efforts and actions, is the organization in the future. Values are the props that will provide organizations, their strength, their power and strengthen the Vision. Depend on the ethical standards and behavior management. All this has become a technique of internal communication and image building.

\section{KEY WORDS}

Visualization process - Communication - Image - Company - Corporate Social Responsibility 


\section{ÍNDICE}

1. Introducción

2. Proceso de Visualización

3. Misión

4. Visión

5. Valores

6. Responsabilidad Social Corporativa

7. Conclusiones

8. Bibliografía

\section{TEXTO}

\section{Introducción}

Aunque en un principio el denominado proceso de visualización, es decir, la implantación de lo que se conoce como misión, visión y valores, respondía a una moda procedente, cómo no, del Gigante del Norte, ahora se ha convertido no sólo en una magnífica técnica de comunicación interna, sino también de creación de imagen. En los albores del siglo XXI, la era de la comunicación, es difícil encontrar una organización privada que no haya establecido su misión, visión y valores y trate con más o menos éxito de divulgarlos entre sus distintos públicos con los que se relaciona o pretende hacerlo. Gracias a dicho esfuerzo, las empresas consiguen o pretenden conseguir cohesionar, estimular y motivar a sus empleados con objeto de que conozcan a la perfección a qué se dedican, qué futuro se quiere construir y cuáles son los valores que rigen su conducta. 
Sin embargo, este proceso de visualización, más que una técnica de comunicación tremendamente eficaz cuando no sólo se elabora de forma correcta, sino también se divulga a través de los diferentes canales con que cuenta una organización, es o debería de ser, por encima de todo, un instrumento de responsabilidad social corporativa. Es, cuando menos curioso, que los términos de responsabilidad, por un lado, y responsabilidad social, por otro, aparezcan como valores en la mayoría de los casos, teniendo en cuenta que el mismo proceso es una herramienta de responsabilidad social corporativa o, como mínimo, el valor principal, que engloba al resto de valores.

El presente artículo presenta el proceso de visualización desde la perspectiva de la responsabilidad social corporativa, es decir, como una tarea ineludible y a la que están obligadas las organizaciones o, mejor dicho, corporaciones, o sea, aquellas organizaciones creadas por la ley con la suficiente capacidad y volumen para liderar el progreso social en todos los órdenes, ya que se trata de un compromiso inherente a la libre asunción de un estado o condición.

\section{Proceso de Visualización}

Esa moda empresarial de contar con una misión, visión y valores, que a priori más de uno creyó pasajera, se ha convertido en algo imprescindible. Así lo considera el empresariado actual que incluso invierte no sólo tiempo y esfuerzo, sino, por supuesto, dinero en encargar a otras organizaciones, dedicadas a ello, la elaboración de ese denominado proceso de visualización, es decir, la redacción de cuál es su misión, visión y valores.

Orientar a las organizaciones y, por supuesto, a su público interno, como brújula hacia el norte deseado, es el principal objetivo de esa serie de reflexiones que reflejan 
la misión, visión y valores de una corporación. Se trata de potenciar el desarrollo de competencias, de estimular y motivar a las personas, de alinear a los empleados con objeto de que avancen en la misma dirección, que no es otra que la consecución de las metas y retos propuestos. Las organizaciones que cuentan con una declaración de estas características logran involucrar al personal, ya que éste conoce cuál es el propósito y líneas integradas de acción del ente al que pertenece. Es decir, al compartir una misma meta y visión, las personas vinculadas a una organización se encuentran mucho más cohesionadas, estimuladas y motivadas y resulta mucho más fácil alcanzar los objetivos marcados. Una declaración explícita y compartida supone orientar mucho mejor las acciones y hacer frente a las posibles adversidades que surjan, puesto que la alta dirección y el resto del personal tienen muy claro su propósito básico, el futuro que quieren construir y en qué se quieren convertir, así como los valores que le dan fortaleza moral para seguir avanzando.

El establecimiento de la misión, visión y valores es, sin duda, un instrumento de comunicación interna, de creación de imagen, y, por supuesto, un ejercicio de responsabilidad social en su doble dimensión, es decir, la referente a la propia actividad de la organización, y la referida a ese conjunto de obligaciones derivadas del tremendo impacto político, económico y medio ambiental que supone la organización en la sociedad.

Es decir, la declaración de misión, visión y valores supone una mayor implicación de los accionistas, directivos y empleados, la concreción de la imagen de excelencia que se desea proyectar a los distintos públicos de la organización, así como un ejercicio de responsabilidad social corporativa ineludible que reportará a la misma excelentes dividendos en todos los ámbitos: imagen, reputación, aceptación social, progreso y, cómo no, rentabilidad económica. 


\section{Misión}

La misión es la razón de existir de la organización, es el propósito central para el que se crea un ente y sintetiza las necesidades que satisface a través de su actividad respecto de la sociedad. Es decir, a la hora de configurar y redactar cuál es la misión de una organización hay que reflejar, sobre todo, la descripción de lo que la organización realiza; a quién está dirigido dicho esfuerzo; y presentar su particularidad, es decir, la singularidad que diferencia a la organización de otras.

La misión debe ser clara, concisa y concreta, debe constituir un propósito asociado a la satisfacción de una necesidad social y debe ser posible.

El concepto de misión y su importancia es aceptado y no difiere mucho entre los expertos. Ahí van unos ejemplos:

James Stoner: la misión es la meta general de la organización, basada en las premisas de la planeación que justifica la existencia de una organización.

Peter Drucker: la misión es la declaración duradera de objetivos que identifica una organización de obra similar.

Félix Martínez Díaz: la misión ha sido confundida a menudo con la responsabilidad social de la empresa.

Sallenave: la responsabilidad de la empresa se establece en términos de utilidad social, lo cual implica un juicio de valor sobre la contribución eventual de la empresa a un conjunto de objetivos sociales o político-económicos, mientras que las misión de 
la empresa no es más que una delimitación del campo de acción que los dirigentes fijan a priori a la empresa y que no implica juicio de valor...

Arellano: la misión delimita el campo de acción de actividades posibles, con el fin de concentrar los recursos de la empresa en un dominio general, o dirigido a un objetivo permanente. Es importante como guía y disciplina.

\section{Visión}

La declaración de visión define y describe el futuro deseado de la organización, es decir, en que se quiere convertir respecto de sus distintos públicos. Es la meta aspiracional de una empresa, el objetivo que quiere alcanzarse.

El propósito de la visión es guiar, controlar y alentar a la organización en su conjunto para alcanzar el estado deseable de la organización. Por supuesto, debe ser factible, compartida y, sobre todo, debe responder a los requerimientos sociales, ya que si se atienden éstos de acuerdo con la norma de cultura de dicha sociedad, la organización será aceptada socialmente y considerada como un ciudadano corporativo, cuyo principal propósito es la cohesión social.

Ahí van las declaraciones de visión de algunas de las empresa más relevantes del país:

Grupo Santander (BSCH): Consolidarse como un gran grupo financiero internacional, que da una rentabilidad creciente a sus accionistas y satisface todas las necesidades financieras de sus clientes. Para ello, cuenta con una fuerte presencia en mercados locales que combina con políticas corporativas y capacidades globales. 
BBVA: “Trabajamos por un futuro mejor para las personas (la Visión de BBVA hace especial énfasis en el concepto de futuro. Toda la actividad del grupo está encaminada a crear futuro para los stakeholders, entendiendo futuro en términos positivos y sostenibles. Futuro es un mañana mejor.")

Telefónica: "Queremos mejorar la vida de las personas, facilitar el desarrollo de los negocios y contribuir al progreso de las comunidades donde operamos, proporcionándoles servicios innovadores basados en las Tecnologías de Información y las Comunicaciones".

Grupo Nutrexpa: Ser lideres. En productos de marca. Que aporten al mismo tiempo: nutrición, salud y sabor. En España, China.

Se observa a simple vista que lo que tratan de reflejar y transmitir las corporaciones es su liderazgo en el sector en el que se desenvuelven. A través de la declaración de visión pretenden comunicar que sus esfuerzos están dirigidos única y exclusivamente a satisfacer una necesidad social y a convertirse en un referente para el público al que dedica su trabajo y constancia. Además, de este modo lograr implicar y motivar a su público interno con objeto de avanzar todos en la misma direccion.

\section{Valores}

¿Qué son los valores? Para explicar este epígrafe recurriremos a Ortega, quien abordó con "rigorosidad" el asunto. Según el filósofo, mientras que en unas ocasiones el valor aparece fundido e indiferenciado con otros problemas, en otras, se desliza disfrazado o camuflado bajo algunas de sus muchas formas particulares o su presencia consiste en una agresiva ausencia. 
Es cierto que el valor se ha ocultado casi siempre o la mayoría de las veces en la idea del bien, es decir, se asocia a lo bueno, a lo agradable, a lo deseable... Sin embargo, los valores son algo objetivo y no subjetivo como dice Ortega, quien añade que “valorar no es dar valor a quien por sí no lo tenía; es reconocer un valor residente en el objeto. No es una quaestio facti, sino una quaestio juris. No es la percatación de un hecho, sino de un derecho. La cuestión del valor es la cuestión de derecho por excelencia. Y nuestro derecho en sentido estricto representa sólo una clase específica de valor: el valor de justicia".

Ahora bien, los valores no son, sino que valen. Es decir, existen en el momento en el que se incorporan a un ente real. Como dice el filósofo son cualidades irreales residentes en las cosas. Uno no se encuentra a la belleza, a la felicidad o a la lealtad paseando por un parque, sino que incorpora, como se ha citado en líneas anteriores, estos valores a un ente real, es decir, a un objeto, a una imagen, a una persona...

Una vez dicho lo que son los valores, es momento de abordar qué valores debe reflejar en su declaración una organización. Aunque la mayor parte de las empresas optan por enumerar entre cinco y siete valores y, en ocasiones, explicarlos, entre los que suele aparecer el de responsabilidad, por un lado, y responsabilidad social, por otro, a nuestro parecer, este último, debería reflejarse como valor principal, del cual se desprenderían una serie de "valores éticos" y otra de "valores profesionales".

\section{Responsabilidad Social Corporativa}

A nuestro entender la Responsabilidad Social Corporativa es el valor principal que engloba al resto de valores. Y entendemos por responsabilidad social corporativa el conjunto de obligaciones inherentes a la libre asunción de un estado o condición, aún no tipificadas por el ordenamiento jurídico positivo, pero cuya fuerza vinculante y 
previa tipificación proceden de la íntima convicción social de que su incumplimiento supone la infracción de la norma de cultura.

Aunque, tal y como hemos avanzado en anteriores artículos, es necesaria una nueva concepción de la responsabilidad, fruto de la actual crisis que atravesamos, no sólo económica, sino política, social y fundamentalmente moral. Esa nueva concepción pasa por exigir no sólo socialmente, sino jurídicamente dicho cumplimiento a las corporaciones. Es decir, entender la responsabilidad social corporativa como un conjunto de obligaciones amparadas coercitivamente tipificadas en instrumentos "ad hoc", cuyo incumplimiento no sólo será sancionado socialmente, sino también jurídicamente.

Al hablar de responsabilidad social corporativa hacemos alusión a esa serie de valores éticos y profesionales, es decir, a la doble dimensión de la responsabilidad social que hace referencia a aquellas obligaciones derivadas de la propia actividad de la corporación y además a las inherentes a ese tremendo impacto político, económico, social y medio ambiental que sobre la civilización tiene dicha organización. Y es que la empresa privada ha superado todas las previsiones y expectativas. De ser una mera anécdota a lo largo de los siglos se ha convertido en el ente artificial que lidera el progreso social en todos los órdenes, es decir, el ente colectivo formal sobre el que reposa la civilización y el que asegura el desenvolvimiento de la misma.

\section{Conclusiones}

El proceso de visualización o declaración de misión, visión y valores es ante todo un ejercicio de responsabilidad social corporativa. Es innegable que se trata de una magnífica herramienta de comunicación interna que no sólo cohesiona y estimula al público interno de una organización y, por ende, supone una estrategia de alineación 
excelente con la que se obtienen notables resultados. Sin embargo, es, como decíamos en anteriores líneas, un ejercicio de responsabilidad social, puesto que por encima de los óptimos resultados que pueden obtenerse como herramienta para motivar a las personas vinculadas, priman los intereses sociales. En este sentido, la declaración debe reflejar qué necesidad de la sociedad cubre, en qué se quiere convertir la organización desde la perspectiva social y qué valor o valores rigen su conducta, y éste no es otro que el de la responsabilidad social corporativa.

La Responsabilidad Social Corporativa no debe aparecer como un valor más, sino como el valor principal que integra al resto de valores. Pues, una organización, integrada por una serie de individuos que deciden agruparse para emprender un proyecto que de forma individual nunca podrían desarrollar, nace por aprobación pública para satisfacer una necesidad de la sociedad. En este sentido, que duda cabe que si es la sociedad quien garantiza la existencia del ente, éste debe no sólo comportarse de una forma acorde a la norma de cultura de dicha sociedad, sino además revertir parte de los beneficios que obtiene de ésta. Se trata pues de satisfacer una obligación social.

\section{Bibliografía}

ALBRECHT, Karl (1996): La Misión de la empresa. Paidós Empresa.

BROWN, Marvin (1992): La ètica en la empresa. Estrategias para la toma de decisiones. Edit. Paidos.

CALDEVILlA DOMÍNGUEZ, David (2004): Las Relaciones Públicas y su fundamentación. Editorial Visionnet. Madrid. 
COSTA, Joan (1993): Imagen pública, una ingeniería social, Fundesco, Madrid.

COSTA, Joan (1995): Comunicación corporativa y revolución de los servicios, Madrid, Ciencias Sociales.

CUESTA, Marta de la y RODRÍGUEZ DUPLÁ, Leonardo (coords.) (2004): Responsabilidad Social Corporativa.

CUESTA, Marta de la, VALOR MARTÍNEZ, Mamen y SANMARTÍN SERRANO, Sergio (2002): Inversiones éticas en empresas socialmente responsables.

FINN, D. (1964): La Empresa y las Relaciones Públicas, Barcelona.

FLORES BAO, F. (1981): Relaciones Públicas. Ciencia de la integración humana, Lima.

G. PERDIGUERO, Tomás (2003): La responsabilidad social de las empresas en un mundo global.

GUARDIA MASSO, Ramón; RENARD, Lluis (1999): Estrategia competitiva y responsabilidad ¿Cómo hacerlas compatibles? Barcelona.

HAYWOOD, Roger (1995): Managing Your Reputation: How to Plan and Run Communications Programmes That Win Friendo and Build Succes.

KELLY, Cathleen S. (1997): Effective Fund-raisin Management, Lawrence Erlbaum Associates, Mahwah, NJ. 
KOTLER, Philip (1997): Marketing Management: Analysis, Planning; Implementatrion and Control, Prentice Hall, Upper Saddle River, NJ.

LESLY, Ph. (1981): Nuevo Manual de Relaciones Públicas, Barcelona. López López, H. (1971): La enseñanza de las Relaciones Públicas, Medellín.

MOORE, H. F. y CANFIELD, B. R. (!980): Relaciones Públicas. Principios, Casos y Problemas, México.

NEWSON, Doug; VANSLYKE, Judyt; KRUCKEBERG, Dean (1996): Wadsworth Publishing Co., Belmont, CA.

Ortega y Gasset, José (1941-1946): Obras Completas. Tomo VI. Quinta Edic. Madrid.

PAINE, Lynn Sharp (2002): Value Shift: Why Companies Must Merge Social and Financial Imperatives to Achieve Superior Performance.

SENGE, Peter ( 1990): La quinta disciplina. El arte y la práctica de la organización abierta al aprendizaje. Ed. Granica.

SOLANO FLETA, L. (1995): Fundamentos de las Relaciones Públicas, Madrid.

VILLAFAÑE GALLEGO, Justo (1993): Imagen positiva. Gestión estratégica de la imagen de las empresas, Madrid, Ediciones Pirámide.

WILSON, Graham K. (1990): Interest groups. Oxford.

XIFRA HERAS, J. (1968): Sociología de las Relaciones Públicas, Barcelona. 